Article

\title{
Ferrocene-Containing Sterically Hindered Phosphonium Salts
}

\author{
Vadim Ermolaev(1), Tatiana Gerasimova, Liliya Kadyrgulova, Ruslan Shekurov, \\ Egor Dolengovski, Aleksandr Kononov, Vasily Miluykov®i), Oleg Sinyashin, \\ Sergei Katsyuba ${ }^{\circledR}$, Yulia Budnikova ${ }^{\circledR}$ and Mikhail Khrizanforov *(D)
}

Arbuzov Institute of Organic and Physical Chemistry, Kazan Scientific Center, Russian Academy of Sciences, 8 Arbuzov St., Kazan 420088, Russia; ermolaewadim@gmail.com (V.E.); tatyanagr@gmail.com (T.G.); liliya-kadyrgulova@mail.ru (L.K.); shekurovruslan@gmail.com (R.S.); cat_space@mail.ru (E.D.); kononovsnz97@gmail.com (A.K.); vasili.miluykov@mail.ru (V.M.); oleg@iopc.ru (O.S.); katsyuba@iopc.ru (S.K.); yulia@iopc.ru (Y.B.)

* Correspondence: khrizanforov@iopc.ru; Tel.: +7-962-5612-219; Fax: +7-843-2732-253

Received: 10 September 2018; Accepted: 22 October 2018; Published: 25 October 2018

\begin{abstract}
The synthesis and physical properties of the series of the ferrocenyl-containing sterically hindered phosphonium salts based on di(tert-butyl)ferrocenylphosphine is reported. Analysis of voltamogramms of the obtained compounds revealed some correlations between their structures and electrochemical properties. The elongation of the alkyl chain at the $\mathrm{P}$ atom as well as replacement of the $\mathrm{Br}^{-}$anion by $\left[\mathrm{BF}_{4}\right]^{-}$shifts the ferrocene/ferrocenium transition of the resulting salts into the positive region. DFT results shows that in the former case, the $\mathrm{Br}^{-}$anion destabilizes the corresponding ion pair, making its oxidation easier due to increased highest occupied molecular orbital (HOMO) energy. Increased HOMO energy for ion pairs with the $\mathrm{Br}^{-}$ion compared to $\mathrm{BF}_{4}{ }^{-}$ are caused by contribution of bromide atomic orbitals to the HOMO. The observed correlations can be used for fine-tuning the properties of the salts making them attractive for applications in multicomponent batteries and capacitors.
\end{abstract}

Keywords: ferrocene; phosphonium salts; ferrocene-containing compounds; DFT calculation; cyclic voltammetry; ionic liquids

\section{Introduction}

Materials that enable selective ion transport under a wide range of conditions (temperature, $\mathrm{pH}$ ) play a key role for chemical separation processes and electrochemical batteries [1,2]. One of the important ways to design such materials is development of synthetic strategies for producing sterically hindered phosphonium salts [2]. Phosphonium-based ionic liquids (ILs) are more thermally stable compared to nitrogen-containing analogues, which provides a wider range of applications (extended reaction temperature range, distillation of products, etc.) and decreases the amount of decomposition products in the reaction mixture [3]. In addition, the absence of an acidic proton, like in imidazolium salts, makes the ILs more stable under the reaction conditions [4]. Introduction of the ferrocenyl $(\mathrm{Fc})$ fragment into ILs leads to unique electrochemical properties [5] (Figure 1), that allows the Fc-containing phosphonium salts to be used for modification of the platinum electrodes surfaces [6-10]. The latter also opens perspectives for using the Fc-based ILs as redox agents in electrolytes for lithium ion batteries [11]. This application requires careful choice of both cationic and anionic components. In this sense, $\left[\mathrm{BF}_{4}\right]^{-}$is attractive because it is one of the smallest and most available (from other anions, such as $\left[\mathrm{PF}_{6}\right]^{-},[\mathrm{NTf}]^{-}$, $\left[\mathrm{SbF}_{6}\right]^{-}$, with comparable properties) weakly coordinating anion [12]. Moreover, potential batteries 
based on the $\left[\mathrm{BF}_{4}\right]^{-}$anion have excellent low-temperature characteristics [13]. In addition, this anion is electrochemically inert in a wide range of potentials [14].

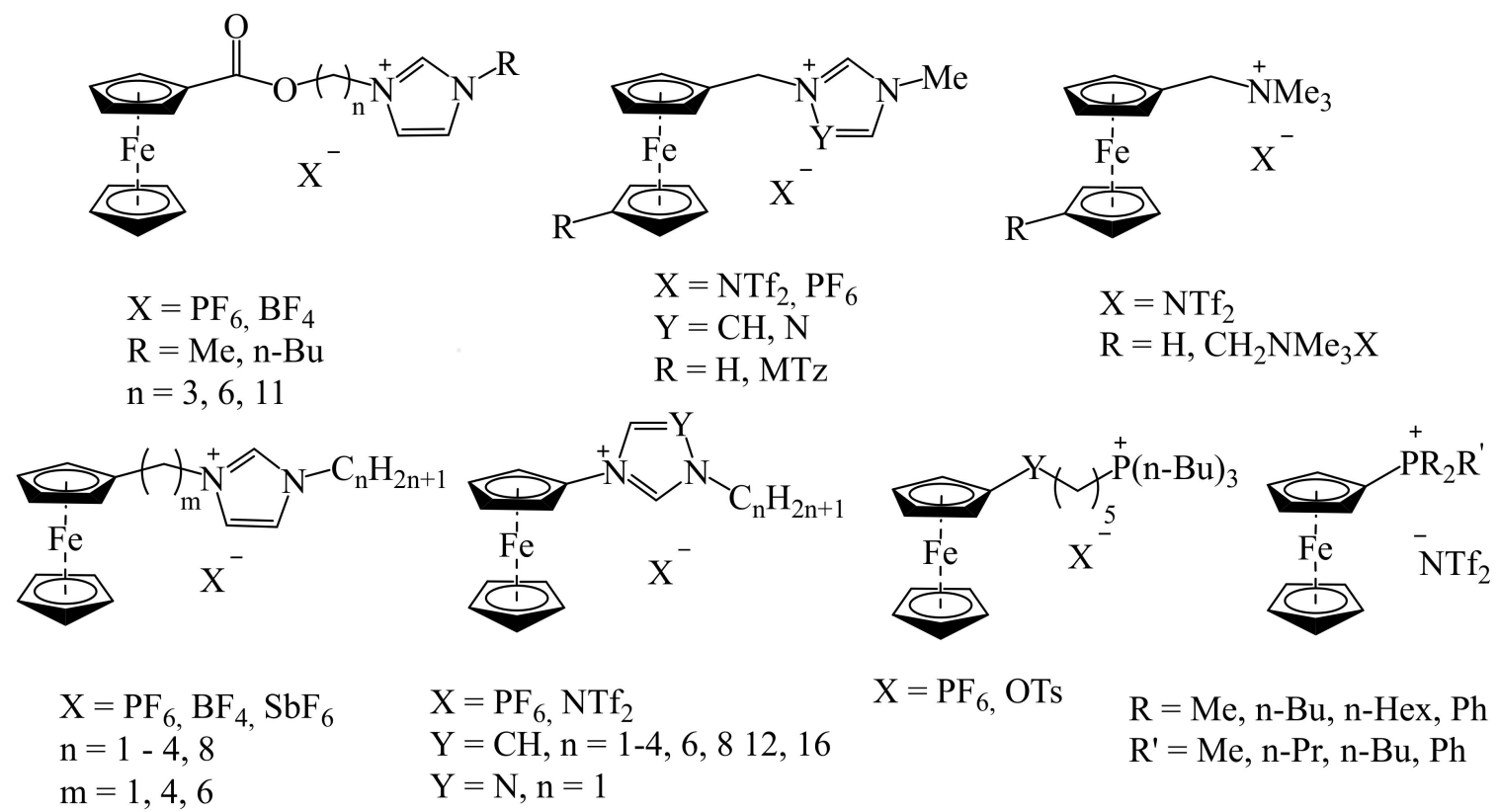

Figure 1. Ferrocenyl (Fc)-containing onium compounds [5-10].

Among Fc-containing ILs, the best known and well-studied are the Fc-containing imidazolium salts (Figure 2). Inclusion of the Fc fragment to the imidazolium compounds increases melting points and viscosities. In these redox-active salts, $F_{C}$ acts as a donor and an imidazolium cation as an acceptor [15]. The inclusion of an organometallic functional groups to the IL structure allows to change the physico-chemical properties of the salt, that enables their use in photoinduced electron transfer in solutions [9], and in the esterification reaction of aldehyde oxidation [16].

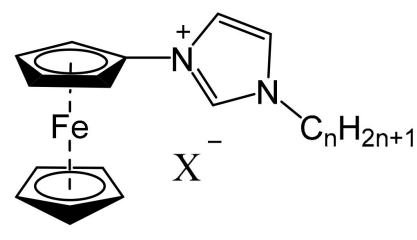

a

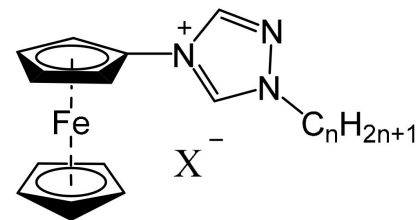

b

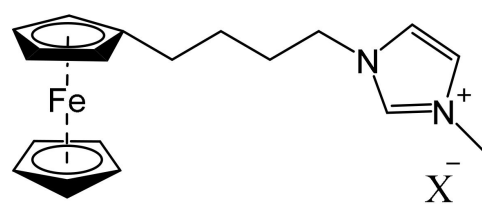

C

Figure 2. 1-Ferrocenyl-3-alkylimidazolium (a); 1-ferrocenyl-4-methyltriazolium (b), and 1-(ferrocenylbutyl)-3-methylimidazolium (c) salts.

One of the main methods to study the redox properties of various organic compounds is voltammetry with chemically modified electrodes. Modified carbon-paste electrodes (CPE) are widely used due to their availability and simple manufacturing [17]. Nevertheless, the preparation of an optimal CPE with high conductivity, wide electrochemical window, and high stability and reproducibility, is still a challenge. Design of CPE requires using chemically inert compounds with high viscosity and ionic conductivity. Such electrodes can significantly increase the selectivity and sensitivity of voltammetric methods [18-20] and at the same time help to obtain important information about energy data [21-23].

A combination of the required properties makes phosphonium salts attractive for design of CPE. However, in the literature there are only a few examples of phosphonium salts used as a binder component for paste electrodes [17]. Thus, the aim of the work is to develop a synthetic strategy for 
obtaining the new Fc-containing phosphonium salts with a sterically hindered cation and to study their physico-chemical properties.

\section{Results and Discussion}

Di(tert-butyl)ferrocenylphosphine has been prepared by the most common way, namely by lithiation of ferrocene with tert-butyllithium and subsequent reaction with di(tert-butyl)chlorophosphine 1 [23]. The starting di(tert-butyl)chlorophosphine has been obtained by the procedure described in [24], i.e., by the reaction of an excess of tert-butylmagnesium chloride with phosphorus trichloride with following separation of the product mixture by distillation under reduced pressure (Scheme 1).

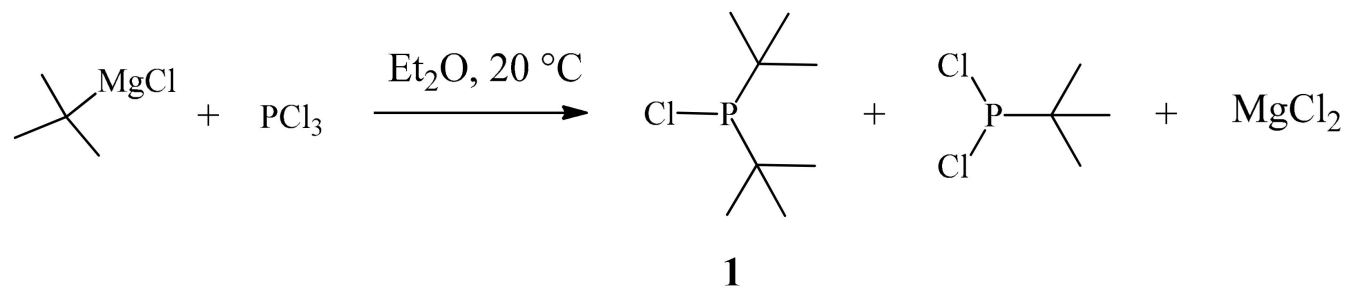

Scheme 1. Preparation of di(tert-butyl)chlorophosphine.

Lithiation with tert-butyllithium usually results in a mixture of mono- and 1,1-dilithiated derivatives. To avoid the formation of dilithiated compounds and obtain only monolithioferrocene, the reaction has been carried out in diethyl ether (Scheme 2).

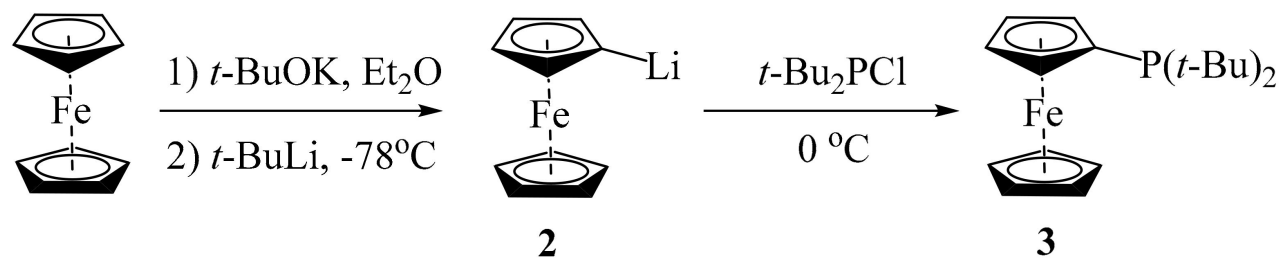

Scheme 2. Preparation of di(tert-butyl)ferrocenylphosphine, 3.

Addition of tert-butyllithium to a solution of ferrocene and $t$-BuOK [25] in diethyl ether results in a color change of the solution from brown to orange, indicating that ferrocene was lithiated. Subsequent slow dropwise addition of di(tert-butyl)chlorophosphine $\mathbf{1}$ leads to precipitation of orange di(tert-butyl)ferrocenylphosphine 3.

Phosphonium salts have been obtained by the reaction of di(tert-butyl)ferrocenylphosphine 3 with alkyl halides in an inert atmosphere (Table 1).

The temperature and time of the reaction are affected by the length of the alkyl group in the haloalkane. Reactions involving haloalkanes with a long alkyl chains proceeded at high temperatures and longer times. For example, the synthesis of methyl(di-tert-butyl)ferrocenylphosphonium iodide 4a has been carried out at $-70{ }^{\circ} \mathrm{C}$, because of the strong exothermic effect, being completed in a few minutes. At the same time, the reaction of di(tert-butyl)ferrocenylphosphine with tetradecyl bromide was carried out at $100{ }^{\circ} \mathrm{C}$ for $6 \mathrm{~h}$. Compared to well-known Fc-containing phosphines with $n$-alkyl substituents, sterically hindered analogs require slightly higher temperatures in the quaternization reaction with alkyl halides [5]. We performed the synthesis of phosphonium salts without any solvent. Under the reaction conditions, the reaction mixture is a viscous liquid. In the case of $\mathbf{4 a}$, the double excess of iodomethane acting as a solvent was used. 
Table 1. Preparation of ferrocene-containing phosphonium salts. Details of the reaction conditions are in the supplementary material.

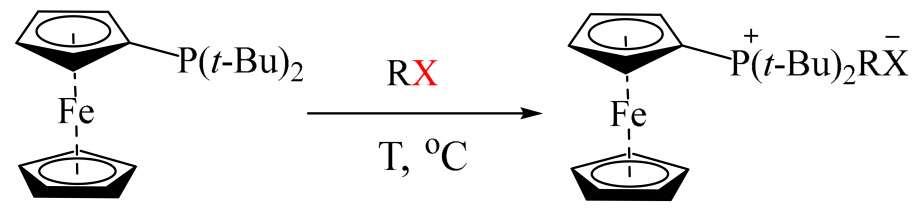

3

\begin{tabular}{ccccc}
\hline No. & $\mathbf{R X}$ & $\mathbf{T}\left({ }^{\circ} \mathbf{C}\right)$ & Reaction Time (h) & Yield (\%) \\
\hline $\mathbf{4 a}$ & $\mathrm{CH}_{3} \mathrm{I}$ & -70 & 0.5 & 62 \\
$\mathbf{4 b}$ & $\mathrm{n}-\mathrm{C}_{3} \mathrm{H}_{7} \mathrm{Br}$ & 70 & 5 & 78 \\
$\mathbf{4 c}$ & $\mathrm{n}-\mathrm{C}_{6} \mathrm{H}_{13} \mathrm{Br}$ & 75 & 5 & 71 \\
$\mathbf{4 d}$ & $\mathrm{n}-\mathrm{C}_{10} \mathrm{H}_{21} \mathrm{Br}$ & 90 & 6 & 69 \\
$\mathbf{4 e}$ & $\mathrm{n}-\mathrm{C}_{14} \mathrm{H}_{29} \mathrm{Br}$ & 100 & 8 & 59 \\
\hline
\end{tabular}

Synthesized Fc-containing phosphonium salts $\mathbf{4 a - e}$ are soluble in dimethylsulfoxide (DMSO) and in methanol and a lower solubility is observed in chloroform. Non-polar solvents such as toluene, benzene, as well as esters and aliphatic solvents do not dissolve 4a-e.

Fc-containing phosphonium salts $4 \mathbf{a}-\mathbf{e}$ are air-stable yellow-brown amorphous substances, however compound $4 \mathbf{e}$ is hygroscopic. With the temperature increase, compounds $4 \mathbf{a}-\mathbf{e}$ gradually soften, become viscous, until they completely turn into liquids. The thermogravimetric/differential scanning calorimetry (TG-DSC) method shows that melting takes place in a rather wide temperature range for compounds $4 \mathbf{a}-\mathbf{d}$ (Table 1). The second peak is registered at a temperature of $165^{\circ} \mathrm{C}(4 \mathbf{a})$, $125^{\circ} \mathrm{C}(4 \mathbf{b}), 141^{\circ} \mathrm{C}(4 \mathbf{c}), 150{ }^{\circ} \mathrm{C}(4 \mathrm{~d})$, and $155^{\circ} \mathrm{C}(4 \mathbf{e})$, with a loss of mass. Most probably, this value corresponds to the decomposition temperature, as during preliminarily measurements of melting point at the Stuart smp30, the blackening of the samples was observed in this temperature range. Characteristic NMR shifts of synthesized salts are presented in Table 2.

Table 2. ${ }^{1} \mathrm{H}$ and ${ }^{31} \mathrm{P}$ chemical shifts of Fc-containing phosphonium salts $4 \mathbf{4}-\mathbf{e}^{\mathrm{a}}$.

\begin{tabular}{cccccc}
\hline No. & Phosphonium Salts & $\begin{array}{c}\delta \mathbf{P}-\mathbf{C H}_{\mathbf{2}} \text { in }{ }^{\mathbf{1}} \mathbf{H} \\
\text { NMR Spectra }\end{array}$ & $\begin{array}{c}\delta^{31} \mathbf{P} \text { NMR } \\
\text { Spectra }\end{array}$ & $\begin{array}{c}\text { Temperature Range } \\
\text { of Melting }\left({ }^{\circ} \mathbf{C}\right)\end{array}$ & $\begin{array}{c}\text { Decomposition } \\
\text { Temperature }\left({ }^{\circ} \mathbf{C}\right)\end{array}$ \\
\hline $\mathbf{4 a}$ & $\mathrm{Fc}_{-} \mathrm{P}^{+}(t-\mathrm{Bu})_{2} \mathrm{CH}_{3} \mathrm{I}^{-}$ & 2.43 & 48.34 & $69-80$ & 165 \\
$\mathbf{4 b}$ & $\mathrm{Fc}_{-} \mathrm{P}^{+}(t-\mathrm{Bu})_{2} \mathrm{C}_{3} \mathrm{H}_{7} \mathrm{Br}^{-}$ & 2.91 & 48.59 & $60-70$ & 125 \\
$\mathbf{4 c}$ & $\mathrm{Fc}^{+} \mathrm{P}^{+}(t-\mathrm{Bu})_{2} \mathrm{C}_{6} \mathrm{H}_{13} \mathrm{Br}^{-}$ & 2.47 & 47.85 & $57-68$ & 141 \\
$\mathbf{4 d}$ & $\mathrm{Fc}_{-} \mathrm{P}^{+}(t-\mathrm{Bu})_{2} \mathrm{C}_{10} \mathrm{H}_{21} \mathrm{Br}^{-}$ & 2.43 & 47.45 & $58-70$ & 150 \\
4e & $\mathrm{Fc}_{-} \mathrm{P}^{+}(t-\mathrm{Bu})_{2} \mathrm{C}_{14} \mathrm{H}_{29} \mathrm{Br}^{-}$ & 2.58 & 47.76 & $61-71$ & 155 \\
\hline
\end{tabular}

${ }^{\mathrm{a}} \mathrm{Fc}=\mathrm{Fe}\left(\eta^{5}-\mathrm{C}_{5} \mathrm{H}_{5}\right)\left(\eta^{5}-\mathrm{C}_{5} \mathrm{H}_{4}\right)$.

The electrochemical properties of $\mathbf{4 a - e}$ in acetonitrile were studied by cyclic voltammetry (Figure 3).

In all cases, reversible transition of ferrocene $\triangleleft$ ferrocenium was observed in the anodic region. It should be noted, that for $\mathbf{4 b}-\mathbf{4 d}$ with the same $\mathrm{Br}^{-}$anion, increase of the length of the alkyl chain at the phosphorus atom is accompanied by the shift of the potential $\mathrm{E}_{1 / 2}$ (or $\mathrm{E}_{\text {semidiff }}$ ) to the anodic region (Table 3). This trend can be characterized by an increase in thermodynamic stability due to a decrease of HOMO energy. Compound 4a with the $\mathrm{I}^{-}$anion is oxidized more positively. It should be noted that the ferrocene fragment is $\mathrm{HOMO}$ energy probe ${ }^{1} \mathrm{E}_{\mathrm{HOMO}}=-\left(\mathrm{E}_{\text {[semidif,ox vs. ferrocenium/ferrocene] }}+4.8 \mathrm{~V}\right)$ [21].

At second oxidation potentials, irreversible oxidation of anionic fragments is observed [26]. In the cathode region (Table 3), an irreversible reduction of the phosphonium fragment is observed for all salts. 
To expand the field of possible application of the obtained salts, the halide anion was replaced by a non-coordinating bulk tetrafluoroborate anion in the reaction of halides with a twofold excess of sodium tetrafluoroborate in ethyl alcohol (Table 4). The oxidation potential of the halide ions is close to $1 \mathrm{~V}$, and the electrochemical window of the salts $4 \mathbf{a}-\mathbf{e}$ is $2.8-3.2 \mathrm{~V}$ (Table 3). Replacing the anion with a tetrafluoroborate ion was expected to increase these values.

The obtained phosphonium salts with tetrafluoroborate anion are dark brown substances, 5a, $\mathbf{5 c}$, and $\mathbf{5 e}$ are viscous, amorphous, and $\mathbf{5 b}$ and $\mathbf{5 d}$ are glassy. The substitution of the halide anion by the tetrafluoroborate anion results in a slight shift of the chemical shift $\left(\delta \mathrm{P}-\mathrm{CH}_{2}\right.$ in ${ }^{1} \mathrm{H}$ NMR Spectra) to the weak fields (Table 5).

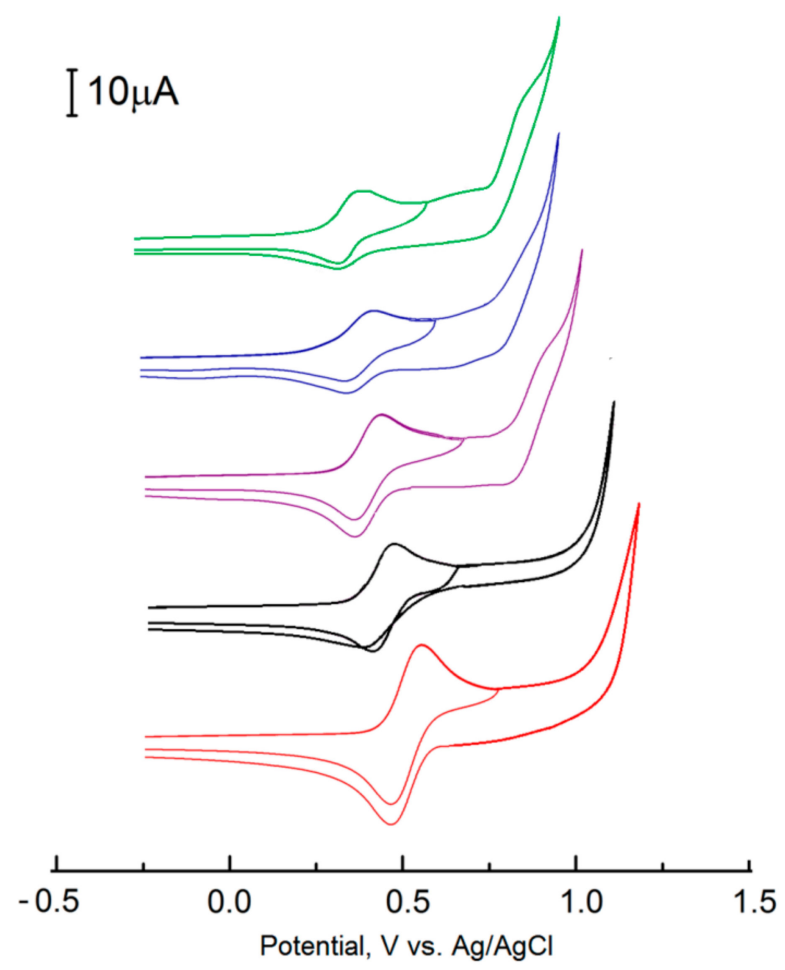

Figure 3. Cyclic voltammograms of $4 \mathrm{a}$ (red), $4 \mathrm{~b}$ (green), $4 \mathrm{c}$ (blue), $4 \mathrm{~d}$ (violet), and $4 \mathrm{e}$ (black) oxidation and re-reduction $(1 \mathrm{mM})$ in $\mathrm{CH}_{3} \mathrm{CN}, \mathrm{Bu}_{4} \mathrm{NBF}_{4}(0.1 \mathrm{M}), \mathrm{RE}: \mathrm{Ag} / \mathrm{AgCl}$, scan rate $100 \mathrm{mV} / \mathrm{s}$.

Table 3. Electrochemical properties of Fc-containing phosphonium salts 4a-4e. Conditions: Room temperature, Working Electrode: Glass-carbon, vs. $\mathrm{Ag} / \mathrm{AgCl}$. Solvent $\mathrm{CH}_{3} \mathrm{CN}$.

\begin{tabular}{|c|c|c|c|c|}
\hline No. & Phosphonium Salts & ${ }^{1} \mathrm{E}_{\text {semidiff }}$ ox $(\mathrm{V})$ & ${ }^{2} E_{\text {onset }}{ }^{o x}(V)$ & ${ }^{1} E_{\text {onset }}{ }^{\text {red }}(\mathrm{V})$ \\
\hline $4 a$ & $\mathrm{Fc}_{\mathrm{C}} \mathrm{P}^{+}(t-\mathrm{Bu})_{2} \mathrm{CH}_{3} \mathrm{I}$ & 0.50 & 1.10 & -1.70 \\
\hline $4 b$ & $\mathrm{Fc}_{-} \mathrm{P}^{+}(t-\mathrm{Bu})_{2} \mathrm{C}_{3} \mathrm{H}_{7} \mathrm{Br}^{-}$ & 0.43 & 0.80 & -2.09 \\
\hline $4 c$ & $\mathrm{Fc}_{-} \mathrm{P}^{+}(t-\mathrm{Bu})_{2} \mathrm{C}_{6} \mathrm{H}_{13} \mathrm{Br}^{-}$ & 0.44 & 0.80 & -2.07 \\
\hline $4 d$ & $\mathrm{Fc}_{\mathrm{C}} \mathrm{P}^{+}(t-\mathrm{Bu})_{2} \mathrm{C}_{10} \mathrm{H}_{21} \mathrm{Br}^{-}$ & 0.45 & 0.84 & -2.06 \\
\hline $4 e$ & $\mathrm{Fc}_{-} \mathrm{P}^{+}(t-\mathrm{Bu})_{2} \mathrm{C}_{14} \mathrm{H}_{29} \mathrm{Br}^{-}$ & 0.46 & 1.16 & -2.05 \\
\hline
\end{tabular}

a The table shows the averaged shifts made after 20 measurements. $\mathrm{Fc}=\mathrm{Fe}\left(\eta^{5}-\mathrm{C}_{5} \mathrm{H}_{5}\right)\left(\eta^{5}-\mathrm{C}_{5} \mathrm{H}_{4}\right) . \mathrm{E}_{1 / 2}$ of ferrocene at the same conditions is equal to $0.42 \mathrm{~V}$.

For all salts $\mathbf{5 a}, \mathbf{5 c}-\mathbf{e}$ electrospray ionization mass spectrometry (ESI) shows a peak at $m / z=87.2$ in the region of negatively charged particles, that indicates a complete replacement of the bromide anion by a tetrafluoroborate anion.

For $5 \mathbf{b}$ and $5 \mathbf{c}$, phase transitions have been registered by TG-DSC, decomposition was observed at $268^{\circ} \mathrm{C}$ and $233^{\circ} \mathrm{C}$ respectively. For compounds $\mathbf{5 d}$ and $\mathbf{5 e}$, melting occurs in the temperature range $40-50{ }^{\circ} \mathrm{C}$ and $60-70{ }^{\circ} \mathrm{C}$, respectively. 
Table 4. Reaction of substitution of anions in Fc-containing phosphonium salts.

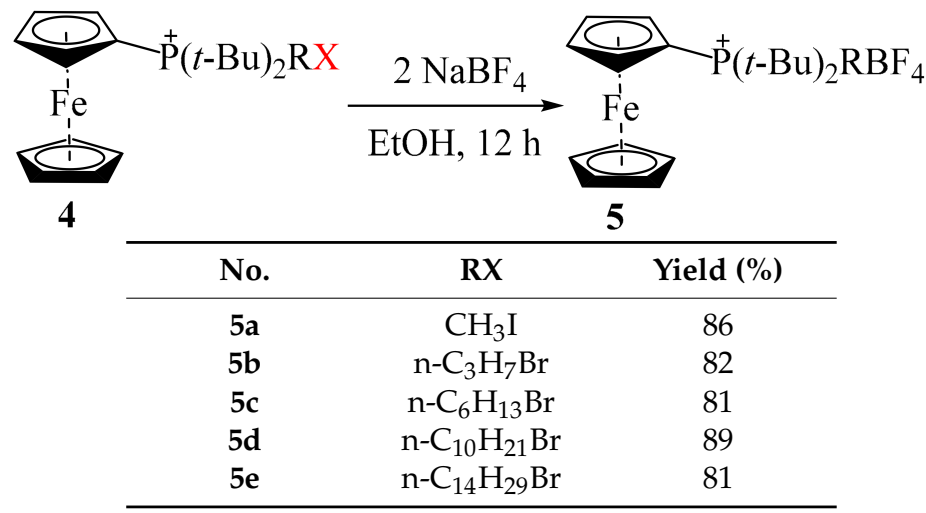

Table 5. ${ }^{1} \mathrm{H}$ and ${ }^{31} \mathrm{P}$ chemical shifts of Fc-containing phosphonium salts $\mathbf{5 a}-\mathbf{e}^{\mathrm{a}}$.

\begin{tabular}{|c|c|c|c|c|c|}
\hline No. & Phosphonium Salts & $\begin{array}{l}\delta \mathrm{P}-\mathrm{CH}_{2} \text { in }{ }^{1} \mathrm{H} \\
\text { NMR Spectra }\end{array}$ & $\begin{array}{l}\delta^{31} \text { P NMR } \\
\text { Spectra }\end{array}$ & $\begin{array}{l}\text { Temperature Range } \\
\text { of Melting }\left({ }^{\circ} \mathrm{C}\right)\end{array}$ & $\begin{array}{c}\text { Decomposition } \\
\text { Temperature }\left({ }^{\circ} \mathrm{C}\right)\end{array}$ \\
\hline $5 \mathbf{a}$ & $\mathrm{Fc}_{-} \mathrm{P}^{+}(t-\mathrm{Bu})_{2} \mathrm{CH}_{3} \mathrm{BF}_{4}^{-}$ & 2.18 & 49.54 & $69-80$ & 164 \\
\hline $5 b$ & $\mathrm{~F}_{\mathrm{C}}-\mathrm{P}^{+}(t-\mathrm{Bu})_{2} \mathrm{C}_{3} \mathrm{H}_{7} \mathrm{BF}_{4}^{-}$ & 2.51 & 47.44 & $39-45$ & 275 \\
\hline $5 c$ & $\mathrm{Fc}_{\mathrm{c}} \mathrm{P}^{+}(t-\mathrm{Bu})_{2} \mathrm{C}_{6} \mathrm{H}_{13} \mathrm{BF}_{4}^{-}$ & 2.52 & 48.11 & $51-52$ & 257 \\
\hline $5 d$ & $\mathrm{Fc}_{-} \mathrm{P}^{+}(t-\mathrm{Bu})_{2} \mathrm{C}_{10} \mathrm{H}_{21} \mathrm{BF}_{4}^{-}$ & 2.56 & 48.32 & $34-38$ & 227 \\
\hline $5 e$ & $\mathrm{Fc}_{-} \mathrm{P}^{+}(t-\mathrm{Bu})_{2} \mathrm{C}_{14} \mathrm{H}_{29} \mathrm{BF}_{4}^{-}$ & 2.57 & 48.54 & $57-60$ & 245 \\
\hline
\end{tabular}

${ }^{\mathrm{a}} \mathrm{FC}=\mathrm{Fe}\left(\eta^{5}-\mathrm{C}_{5} \mathrm{H}_{5}\right)\left(\eta^{5}-\mathrm{C}_{5} \mathrm{H}_{4}\right)$.

Analysis of cyclic voltammograms of $5 \mathbf{a}-\mathbf{e}$ in acetonitrile shows that the phosphonium salts with $\left[\mathrm{BF}_{4}\right]^{-}$anion (Figure 4, Table 6) are oxidized more positively compared to the $\mathrm{Br}^{-}$salts (Figure 3, Table 3), which is also characterized by an increase in thermodynamic stability with an increase in the length of the alkyl tail at the phosphorus atom, potential $\mathrm{E}_{1 / 2}$ (or $\mathrm{E}_{\text {semidiff }}$ ).

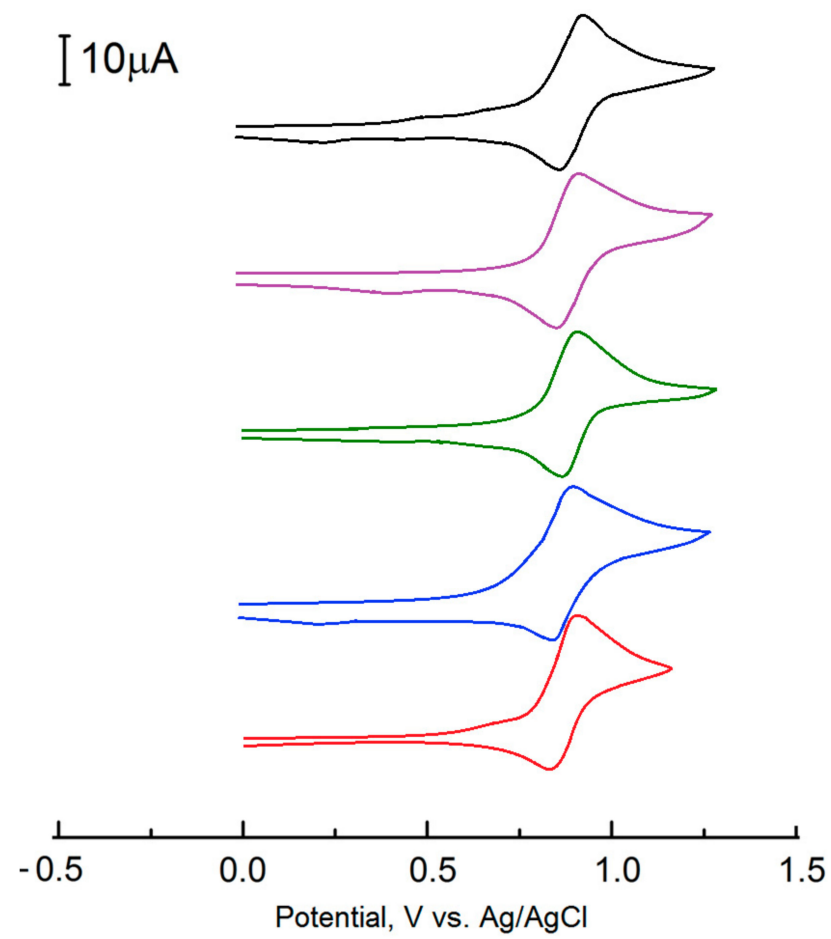

Figure 4. Cyclic voltammogram of $5 \mathbf{a}$ (red), 5b (blue), 5c (green), 5d (violet), 5e (black) oxidation and re-reduction $(1 \mathrm{mM})$ in $\mathrm{CH}_{3} \mathrm{CN}, \mathrm{Bu}_{4} \mathrm{NBF}_{4}(0.1 \mathrm{M})$, reference electrode (RE) $\mathrm{Ag} / \mathrm{AgCl}$, scan rate $100 \mathrm{mV} / \mathrm{s}$. 
Table 6. Electrochemical properties of ferrocene-containing phosphonium salts. Conditions: room temperature, working electrode: glass-carbon, $\mathrm{RE}: \mathrm{Ag} / \mathrm{AgCl}$, solvent: $\mathrm{CH}_{3} \mathrm{CN}^{\mathrm{a}}$.

\begin{tabular}{|c|c|c|c|c|}
\hline No. & Phosphonium Salts & ${ }^{1} E_{\text {semidiff }}{ }^{\text {ox }}(\mathrm{V})$ & ${ }^{2} E_{\text {onset }}{ }^{o x}(V)$ & ${ }^{1}$ E $_{\text {onset }}{ }^{\text {red }}(\mathrm{V})$ \\
\hline $5 a$ & $\mathrm{Fc}-\mathrm{P}^{+}(t-\mathrm{Bu})_{2} \mathrm{CH}_{3} \mathrm{BF}_{4}^{-}$ & 0.89 & 2.95 & -1.82 \\
\hline $5 b$ & $\mathrm{Fc}_{\mathrm{C}} \mathrm{P}^{+}(t-\mathrm{Bu})_{2} \mathrm{C}_{3} \mathrm{H}_{7} \mathrm{BF}_{4}-$ & 0.89 & 2.95 & -1.94 \\
\hline $5 c$ & $\mathrm{Fc}_{-} \mathrm{P}^{+}(t-\mathrm{Bu})_{2} \mathrm{C}_{6} \mathrm{H}_{13} \mathrm{BF}_{4}^{-}$ & 0.89 & 2.95 & -2.05 \\
\hline $5 d$ & $\mathrm{Fc}_{\mathrm{C}}-\mathrm{P}^{+}(t-\mathrm{Bu})_{2} \mathrm{C}_{10} \mathrm{H}_{21} \mathrm{BF}_{4}^{-}$ & 0.90 & 2.96 & -2.20 \\
\hline $5 e$ & $\mathrm{Fc}-\mathrm{P}^{+}(t-\mathrm{Bu})_{2} \mathrm{C}_{14} \mathrm{H}_{29} \mathrm{BF}_{4}^{-}$ & 0.91 & 2.97 & -2.40 \\
\hline
\end{tabular}

${ }^{a}$ The table shows the averaged shifts made after 20 measurements. ${ }^{a} \mathrm{Fc}=\mathrm{Fe}\left(\eta^{5}-\mathrm{C}_{5} \mathrm{H}_{5}\right)\left(\eta^{5}-\mathrm{C}_{5} \mathrm{H}_{4}\right)$.

The series of ILs with different lengths of alkyl fragment at phosphorus atoms were considered quantum chemically (Figure 5). To simplify the computations, only the most stable all-trans conformations of alkyl moieties of $\left[\mathrm{Fc}-\mathrm{P}(t-\mathrm{Bu})_{2} \mathrm{Alk}\right]^{+}$cations were regarded. This planar zigzag conformation is preferred for the nearest to the phosphorus atom part of the alkyl chain in crystals of closely related phosphonium salts and is the most energetically stable form of isolated tetraalkylphosphonium cations according to quantum chemical computations [27]. For m1, m5, and $\mathbf{m} 9$ models with the shortest, medium, and the longest alkyl chains, respectively, three possible conformations with different torsion (Cp)CCPC(Alk) angles were optimized (Figure 5). In a and c cases, quantum chemical optimization leads to structure with eclipsed Fc conformation, whereas in conformer $\mathbf{b}$, the Fc moiety adopts a staggered conformation. The computed energy differences between $\mathbf{a}$ and $\mathbf{b}$ conformers with the alkyl moiety $\mathrm{R}$ turned towards the $\mathrm{Fe}^{2+}$ ion do not exceed 1 $\mathrm{kcal} / \mathrm{mol}$. The conformer $\mathbf{b}$ is the most stable form for the model $\mathbf{m} \mathbf{1}$, whereas for the models $\mathbf{m} \mathbf{5}$ and $\mathbf{m} \mathbf{9}$, conformation $\mathbf{a}$ is energetically preferred. In all cases, the conformer $\mathbf{c}$ was predicted to be less energetically stable as compared to $\mathbf{a}$ and $\mathbf{b}$ by $\sim 4 \mathrm{kcal} / \mathrm{mol}$.

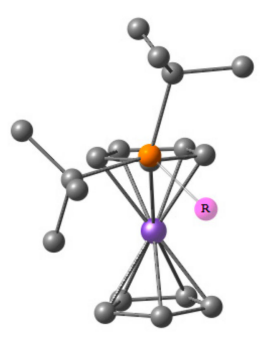

(a)

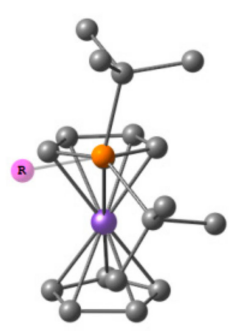

(b)

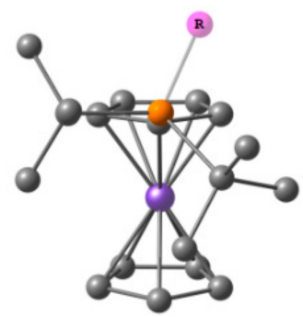

(c)

Figure 5. Considered conformations (a-c) of cation part of IL models, $\mathrm{R}=\mathrm{Me}(\mathbf{m} 1)$, Et $(\mathbf{m} 2), \operatorname{Pr}(\mathbf{m} 3)$, $\mathrm{Bu}(\mathbf{m} 4), \mathrm{C}_{6} \mathrm{H}_{13}(\mathbf{m} 5) \mathrm{C}_{7} \mathrm{H}_{15}(\mathbf{m} 6), \mathrm{C}_{10} \mathrm{H}_{21}$ (m7), $\mathrm{C}_{13} \mathrm{H}_{27}(\mathbf{m} 8), \mathrm{C}_{14} \mathrm{H}_{29}$ (m9).

Energies of frontier molecular orbitals (FMOs) computed for a conformation of $\mathbf{m} \mathbf{1}-\mathbf{m} \mathbf{9}$ models are collected in Table 7. According to our computations, elongation of the alkyl chain shifts both the highest occupied (HOMO) and the lowest unoccupied molecular orbitals (LUMO). This effect is slightly more pronounced for LUMO resulting in a weak increase of the HOMO-LUMO gap. 
Table 7. Absolute HOMO and LUMO energies and HOMO-LUMO gaps (in eV) calculated for the models $\mathbf{m} 1-\mathbf{m} 9$ a.

\begin{tabular}{|c|c|c|c|}
\hline Compound & HOMO & LUMO & LUMO-HOMO Gap \\
\hline $\mathrm{Fc}_{-} \mathrm{P}^{+}(t-\mathrm{Bu})_{2} \mathrm{CH}_{3}(\mathbf{m} \mathbf{1})$ & -9.24 & -3.58 & 5.67 \\
\hline $\mathrm{Fc}-\mathrm{P}^{+}(t-\mathrm{Bu})_{2} \mathrm{CH}_{3} \mathrm{BF}_{4}^{-}$ & -6.61 & -0.91 & 5.70 \\
\hline $\mathrm{Fc}_{-} \mathrm{P}^{+}(t-\mathrm{Bu})_{2} \mathrm{CH}_{3} \mathrm{Br}^{-}$ & -4.93 & -0.74 & 4.19 \\
\hline $\mathrm{Fc}_{\mathrm{c}} \mathrm{P}^{+}(t-\mathrm{Bu})_{2} \mathrm{C}_{2} \mathrm{H}_{5}(\mathbf{m} 2)$ & -9.24 & -3.56 & 5.68 \\
\hline $\mathrm{Fc}_{-} \mathrm{P}^{+}(t-\mathrm{Bu})_{2} \mathrm{C}_{3} \mathrm{H}_{7}(\mathrm{~m} 3)$ & -9.22 & -3.53 & 5.69 \\
\hline $\mathrm{Fc}_{\mathrm{c}} \mathrm{P}^{+}(t-\mathrm{Bu})_{2} \mathrm{C}_{4} \mathrm{H}_{8}(\mathbf{m} 4)$ & -9.20 & -3.51 & 5.69 \\
\hline $\mathrm{Fc}_{c}-\mathrm{P}^{+}(t-\mathrm{Bu})_{2} \mathrm{C}_{6} \mathrm{H}_{13}(\mathrm{~m} 5)$ & -9.18 & -3.49 & 5.69 \\
\hline $\mathrm{Fc}_{-} \mathrm{P}^{+}(t-\mathrm{Bu})_{2} \mathrm{C}_{7} \mathrm{H}_{15}(\mathbf{m} \mathbf{6})$ & -9.18 & -3.49 & 5.69 \\
\hline $\mathrm{Fc}_{-} \mathrm{P}^{+}(t-\mathrm{Bu})_{2} \mathrm{C}_{10} \mathrm{H}_{21}(\mathbf{m} 7)$ & -9.17 & -3.48 & 5.69 \\
\hline $\mathrm{Fc}_{-} \mathrm{P}^{+}(t-\mathrm{Bu})_{2} \mathrm{C}_{13} \mathrm{H}_{27}(\mathbf{m} 8)$ & -9.16 & -3.48 & 5.69 \\
\hline $\mathrm{Fc}_{-} \mathrm{P}^{+}(t-\mathrm{Bu})_{2} \mathrm{C}_{14} \mathrm{H}_{29}(\mathbf{m} 9)$ & -9.16 & -3.47 & 5.69 \\
\hline $\mathrm{Fc}_{\mathrm{C}} \mathrm{P}^{+}(t-\mathrm{Bu})_{2} \mathrm{C}_{14} \mathrm{H}_{29} \mathrm{BF}_{4}^{-}$ & -6.67 & -0.96 & 5.71 \\
\hline $\mathrm{Fc}_{\mathrm{C}}-\mathrm{P}^{+}(t-\mathrm{Bu})_{2} \mathrm{C}_{14} \mathrm{H}_{29} \mathrm{Br}^{-}$ & -5.01 & -0.73 & 4.28 \\
\hline
\end{tabular}

${ }^{\mathrm{a}} \mathrm{FC}=\mathrm{Fe}\left(\eta^{5}-\mathrm{C}_{5} \mathrm{H}_{5}\right)\left(\eta^{5}-\mathrm{C}_{5} \mathrm{H}_{4}\right)$.

The computations showed similar composition of FMOs for $\mathrm{m} 1$ and $\mathrm{m} 9$. In both cases, HOMO is predicted to be localized on the Fc moiety of the cation, whereas LUMO is contributed also by $\mathrm{P}-\mathrm{C}$ bond and atomic orbitals (AOs) of $t$-Bu and nearest carbon atom of alkyl group (Figure 6).

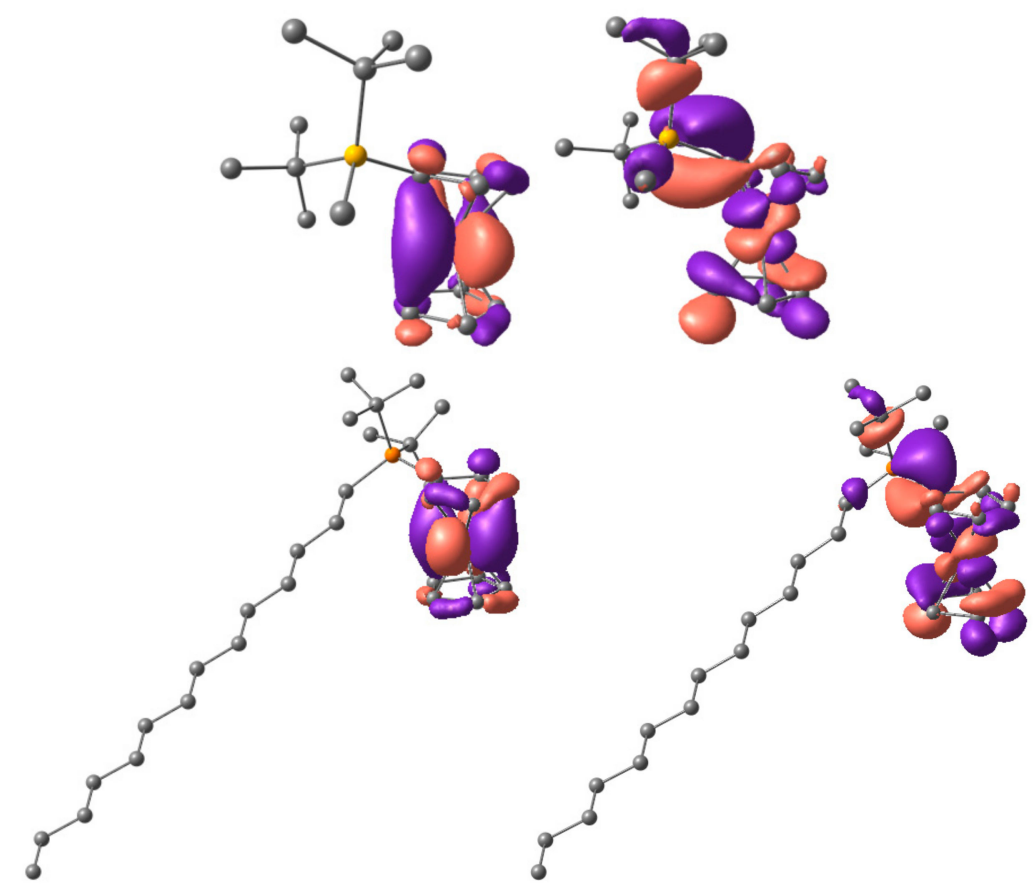

Figure 6. HOMO (left) and LUMO (right) of $\mathbf{m} 1$ (top) and $\mathbf{m} 9$ (bottom).

For $\mathbf{m} 1$ and $\mathbf{m}$ 9, ion pairs with $\mathrm{Br}^{-}$and $\left[\mathrm{BF}_{4}\right]^{-}$counterions were optimized (Figure 7). According to our computations, the energy of ion pairing is higher by $6-8 \mathrm{kcal} / \mathrm{mol}$ for $\mathrm{Br}^{-}$anion compared to $\left[\mathrm{BF}_{4}\right]^{-}\left(84 \mathrm{vs} .78 \mathrm{kcal} / \mathrm{mol}\right.$ for Fc- $\mathrm{P}^{+}(t-\mathrm{Bu})_{2} \mathrm{CH}_{3}$ and 85 vs. 77 for Fc- $\mathrm{P}^{+}(t-\mathrm{Bu})_{2} \mathrm{C}_{14} \mathrm{H}_{29}$ $\mathrm{kcal} / \mathrm{mol})$. 


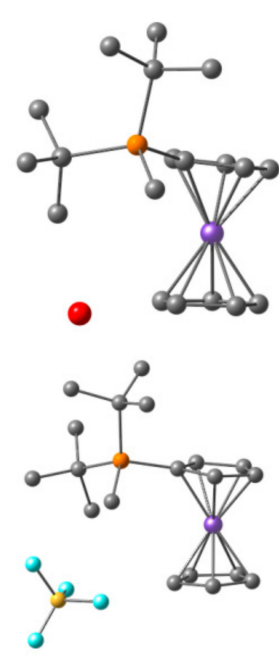

(a)

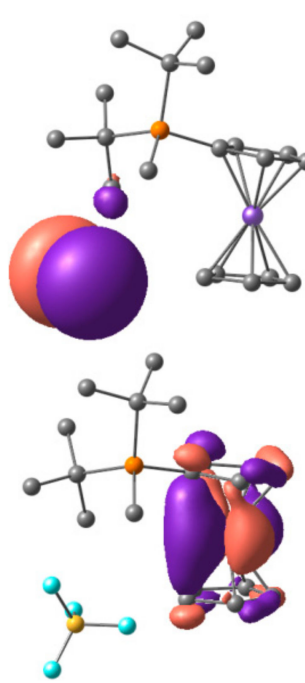

(b)

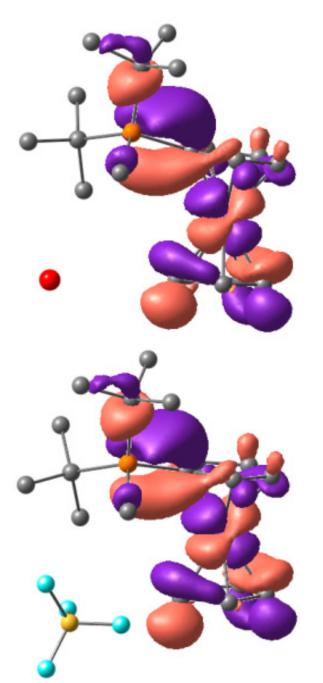

(c)

Figure 7. Structures of considered ion pairs of $\mathbf{m} \mathbf{1}$ (a) with $\mathrm{Br}^{-}$(top) and $\left[\mathrm{BF}_{4}\right]^{-}$(bottom) anions and corresponding HOMO (b) and LUMO (c).

The ion pairing increases the energies of both $\mathrm{HOMO}$ and LUMO; in the case of $\left[\mathrm{BF}_{4}\right]^{-}$anion, the shift is almost parallel, being slightly more pronounced for LUMO, resulting in quite modest increasing of the HOMO-LUMO gap compared to cations. In contrast, $\mathrm{Br}^{-}$much more essentially affects the HOMO, making the oxidation of bromide salts easier. The resulting HOMO-LUMO gap is significantly decreased compared to cations and bromides (Table 7). Such pronounced effect in the latter case is caused by contribution of $\mathrm{Br}^{-}$AOs to $\mathrm{HOMO}$ (Figure 5). Similar localization of HOMO and LUMO is predicted also for $\mathbf{m} 9$ with $\left[\mathrm{BF}_{4}\right]^{-}$and $\mathrm{Br}^{-}$anions. In both cases, elongation of alkyl chain of cationic moiety leads to reduced HOMO energy (from -4.93 to -5.01 in the $\mathrm{Br}^{-}$case and from -6.61 to -6.67 for $\left[\mathrm{BF}_{4}\right]^{-}$), that is in accordance with the experimental trends observed electrochemically. Indeed, according to the abovementioned equation ${ }^{1} \mathrm{E}_{\mathrm{HOMO}}=-\left(\mathrm{E}_{\text {[semidif,ox vs. ferrocenium } / \text { ferrocene] }}\right.$ $+4.8 \mathrm{~V})$ the latter is equal to -5.23 for Fc- $\mathrm{P}^{+}(t-\mathrm{Bu})_{2} \mathrm{C}_{3} \mathrm{H}_{7} \mathrm{Br}^{-}$and -5.26 for Fc- $\mathrm{P}^{+}(t-\mathrm{Bu})_{2} \mathrm{C}_{14} \mathrm{H}_{29} \mathrm{Br}^{-}$; -5.69 for Fc- $\mathrm{P}^{+}(t-\mathrm{Bu})_{2} \mathrm{CH}_{3} \mathrm{BF}_{4}{ }^{-}$and -5.71 for $\mathrm{Fc}_{-} \mathrm{P}^{+}(t-\mathrm{Bu})_{2} \mathrm{C}_{14} \mathrm{H}_{29} \mathrm{BF}_{4}{ }^{-}$.

\section{Materials and Methods}

\subsection{Electrochemistry}

Cyclic voltammograms were recorded with a BASi Epsilon E2P (Bioanalytical Systems, Inc., West Lafayette, IN, USA) potentiostat. The device comprises a measuring unit, PC Dell Optiplex 320 (Bioanalytical Systems, Inc.) with the Epsilon-EC-USB-V200 software (Bioanalytical Systems, Inc.). Tetrabutylammonium tetrafluoroborate $\left(\mathrm{C}_{4} \mathrm{H}_{8}\right)_{4} \mathrm{NBF}_{4}$ was used as background electrolyte. The working electrode was a stationary disc glassy-carbon electrode (the surface area of $6 \mathrm{~mm}^{2}$ ). $\mathrm{Ag} / \mathrm{AgCl}(0.01 \mathrm{M} \mathrm{KCl})$ (Bioanalytical Systems, Inc.) was used as a reference electrode. The reference electrode was connected with the cell solution by a modified Luggin capillary filled with the supporting electrolyte solution $\left(0.1 \mathrm{M} \mathrm{Bu}_{4} \mathrm{NBF}_{4}\right.$ in $\left.\mathrm{CH}_{3} \mathrm{CN}\right)$. Thus, the reference electrode assembly had two compartments, each terminated with an ultra-fine glass frit to separate the $\mathrm{AgCl}$ from the analyte. A platinum wire was used as an auxiliary electrode. The scan rate was $100 \mathrm{mV} / \mathrm{s}$. The measurements were performed in a temperature-controlled electrochemical cell (volume from $1 \mathrm{~mL}$ to $5 \mathrm{~mL}$ ) in an inert gas atmosphere $\left(\mathrm{N}_{2}\right)$. Between measurements or prior to a registration of a voltammetry wave, the solution was actively stirred with a magnetic stirrer under constant inflow of an inert gas that was run through a dehydrating system, and then through a nickel-based purification system BI-GAS cleaner (OOO Modern Laboratory Equipment, Novosibirsk, Russia) to remove trace quantities of oxygen. 


\subsection{NMR Experiments}

The NMR spectra were registered on the equipment of Assigned Spectral-Analytical Center of FRC Kazan Scientific Center of RAS, namely on multi-nuclear spectrometer Bruker AVANCE-400 (BRUKER BioSpin, Rheinstetten, Germany) (400.1 MHz $\left({ }^{1} \mathrm{H}\right), 100.6 \mathrm{MHz}\left({ }^{13} \mathrm{C}\right)$ and $\left.162.0 \mathrm{MHz}\left({ }^{31} \mathrm{P}\right)\right)$. Chemical shifts are given in parts per million relative to $\mathrm{SiMe}_{4}\left({ }^{1} \mathrm{H}\right.$, internal) and $85 \% \mathrm{H}_{3} \mathrm{PO}_{4}$ $\left({ }^{31} \mathrm{P}\right.$, external).

\subsection{Thermogravimetric/Differential Scanning Calorimetry (TG-DSC)}

Thermogravimetric analysis was performed on the NETZSCH STA 449F3 (NETZSCH-Gerätebau $\mathrm{GmbH}$, Selb, Germany) with a heating rate of $10 \mathrm{~K}$ per minute up to $400{ }^{\circ} \mathrm{C}$ under argon atmosphere.

\subsection{Calculations}

All calculations were performed with the Gaussian 16 suite of programs [28]. The hybrid PBE0 functional [29] and the Ahlrichs' triple- $\zeta$ def-TZVP AO basis set [30] were used for optimization of all structures. In all geometry optimizations, the D3 approach [31] to describe the London dispersion interactions together with the Becke-Johnson (BJ) damping function [32-34] were employed as implemented in the Gaussian 16 program.

\subsection{Mass-Spectra}

Mass Electrospray ionization mass spectrometry (ESI-MS) was performed on the AmazonX mass spectrometer (Bruker Daltonics, Bremen, Germany). The measurements were carried out in the positive/negative ion detection mode in the $m / z$ range from 100 to 1000 . The voltage on the capillary was 140 V. Data was processed using the DataAnalysis 4.0 program (Bruker Daltonics).

\subsection{Materials and Reagents}

All the work related to the preparation of the initial reagents, the synthesis and the release of products was carried out in an inert atmosphere using standard Schlenk apparatus. All solvents and purchased reagents were absolute by the appropriate methods, mainly by distillation in an inert atmosphere.

t-BuLi (1.6 M solution) (Sigma Aldrich, St. Louis, MO, USA) was used without a preliminary purification.

\subsection{Synthesis (General Procedure)}

\subsubsection{Synthesis of Di(tert-Butyl)Ferrocenylphosphine}

In a two-necked Schlenk vessel equipped with a magnetic stirrer, ferrocene (10.3 mol, $1.923 \mathrm{~g})$ and $t$-BuOK (1.55 mmol, $0.173 \mathrm{~g}$ ) were placed, the mixture was dissolved in $150 \mathrm{~mL}$ of diethyl ether. The solution was cooled to $-78^{\circ} \mathrm{C}$. A solution of $t$-BuLi $(10.3 \mathrm{mmol})$ was added over 10-15 min. Stirring of the reaction mixture was carried out at $-70{ }^{\circ} \mathrm{C}$ for $1 \mathrm{~h}$. An orange precipitate of di(tert-butyl)ferrocenylphosphine was observed to form. The reaction mixture then was warmed to $0^{\circ} \mathrm{C}$ and $(t-\mathrm{Bu})_{2} \mathrm{PCl}(5.15 \mathrm{mmol}, 0.98 \mathrm{~mL})$ was added dropwise. After the completion of the dropping, the cooling bath was removed and the reaction mixture was warmed to room temperature. $\mathrm{After}_{\mathrm{Et}} \mathrm{O}$ was removed in vacuum theresidue was dissolved in $200 \mathrm{~mL}$ of petroleum ether and filtered through a short silica column. Removal of the solvents yield a dark-brown solid $2.431 \mathrm{~g}(71 \%)$. ${ }^{31} \mathrm{P}$ (Petroleum ether, $\delta$, ppm) NMR: 28.5 (s). [5]

\subsubsection{Method for the Synthesis of Methyl (Di-tert-butyl)Ferrocenylphosphonium Iodide (4a)}

Iodomethane $(0.191 \mathrm{~mL}, 3.06 \mathrm{mmol})$ was added to di(tert-butyl)ferrocenylphosphine $(0.507 \mathrm{~g}$, $1.53 \mathrm{mmol}$ ) with stirring. The precipitation of a brown solid was observed. The product is then washed 
2 times with $20 \mathrm{~mL}$ of petroleum ether and 2 times with $20 \mathrm{~mL}$ of diethyl ether. The precipitate is filtered out, the solvent residues are removed in vacuo. Yield $0.449 \mathrm{~g}(62 \%)$, m.p. $=74.1^{\circ} \mathrm{C}$.

3.7.3. Synthesis of Propyl-, Hexyl-, Decyl-, Tetradecyl (Di-tert-butyl)ferrocenylphosphonium Bromides (4b-e)

An equivalent amount of alkyl bromide was added to di(tert-butyl)ferrocenylphosphine. The reaction mass was stirred at $70{ }^{\circ} \mathrm{C}(4 \mathbf{b}), 75^{\circ} \mathrm{C}(4 \mathbf{c}), 90^{\circ} \mathrm{C}(4 \mathbf{d})$, and $100{ }^{\circ} \mathrm{C}(4 \mathbf{e})$ for $5 \mathrm{~h}$. The product was then washed with 2 portions of $20 \mathrm{~mL}$ of petroleum ether and 2 portions of $20 \mathrm{~mL}$ of diethyl ether. The precipitate was filtered out and the solvent residues were removed in vacuo.

3.7.4. Synthesis of Methyl-, Propyl-, Hexyl-, Decyl-, Tetradecyl-(di-tert-butyl)ferrocenylphosphonium Tetrafluoroborates $(\mathbf{5 a}-\mathbf{e})$

Salts (5a-e) were dissolved in $10 \mathrm{~mL}$ of ethyl alcohol and a twofold excess of sodium tetrafluoroborate solution in ethyl alcohol was added to them. The reaction mixture was stirred for $12 \mathrm{~h}$. The solvent was evaporated in vacuo, and the salt was dissolved in $20 \mathrm{~mL}$ of methylene chloride and washed with distilled water. The organic phase was separated and dried over magnesium sulfate. The solvent is evaporated, and the salt is dried under vacuum at $50{ }^{\circ} \mathrm{C}$ for $8 \mathrm{~h}$. For other details, see the Supplementary Material.

\section{Conclusions}

A synthetic methodology for the preparation of new Fc-containing sterically hindered phosphonium ILs based on di(tert-butyl)ferrocenylphosphine is described. Electrochemical measurements showed that with increasing length of the alkyl fragment at the phosphorus atom, the potential shifts to the anode region. The replacement of the bromide anion by $\left[\mathrm{BF}_{4}\right]^{-}$significantly shifts the ferrocene/ferrocenium transition into the positive region of the resulting salts. Such a pronounced effect is caused by a stronger ion pairing with $\mathrm{B} \mathrm{Br}^{-}$anion. According to our computations, in the ion pairs with $\mathrm{Br}^{-}$, the HOMOs are contributed by the counter-ion. For both $\mathrm{Br}^{-}$and $\left[\mathrm{BF}_{4}\right]^{-}$cases, elongation of the alkyl chain with a cationic moiety leads to a reduction of HOMO energy that is in accordance with the experimental trends observed electrochemically.

The electrochemical properties of the newly synthesized Fc-containing phosphonium salts mean that they will represent attractive alternative components for batteries and capacitors. This opens additional potential for using Fc-based ILs as redox agents in electrolytes for lithium ion batteries.

Supplementary Materials: The following are available online: Experimental procedures; NMR spectra of synthesized compounds; ESI-MS spectra of synthesized compounds and TG-DSC curves of synthesized compounds.

Author Contributions: V.E., L.K. developed synthetic procedure of the phosphonium salts; T.G. and S.K. performed quantum-chemical studies, conducted discussion of the results; R.S., E.D. and A.K., performed voltammetric studies; V.M., O.S., Y.B. and M.K. generated the basic idea of the study, summarized and discussed the results of individual studies, preparation and writing of the article.

Funding: This work was supported by the Russian Science Foundation No. 18-73-10139.

Acknowledgments: Authors are grateful to A. Khamatgalimov for TG-DSC analysis.

Conflicts of Interest: The authors declare no conflict of interest.

\section{References}

1. Womble, C.T.; Kang, J.; Hugar, K.M.; Coates, G.W.; Bernhard, S.; Noonan, K.J. Rapid Analysis of Tetrakis (dialkylamino) phosphonium Stability in Alkaline Media. Organometallics 2017, 36, 4038-4046. [CrossRef]

2. Kreuer, K.D. Ion conducting membranes for fuel cells and other electrochemical devices. Chem. Mater. 2013, 26, 361-380. [CrossRef]

3. Dake, S.A.; Kulkarni, R.S.; Kadam, V.N.; Modani, S.S.; Bhale, J.J.; Tathe, S.B.; Pawar, R.P. Phosphonium ionic liquid: A novel catalyst for benzyl halide oxidation. Synth. Commun. 2009, 39, 3898-3904. [CrossRef] 
4. Tseng, M.C.; Kan, H.C.; Chu, Y.H. Reactivity of trihexyl (tetradecyl) phosphonium chloride, a room-temperature phosphonium ionic liquid. Tetrahedron Lett. 2007, 48, 9085-9089. [CrossRef]

5. Kübler, P.; Sundermeyer, J. Ferrocenyl-phosphonium ionic liquids-Synthesis, characterisation and electrochemistry. Dalton Trans. 2014, 43, 3750-3766. [CrossRef] [PubMed]

6. Weaver, J.E.; Breadner, D.; Deng, F.; Ramjee, B.; Ragogna, P.J.; Murray, R.W. Electrochemistry of ferrocene-functionalized phosphonium ionic liquids. J. Phys. Chem. C 2011, 115, 19379-19385. [CrossRef]

7. Ghilane, J.; Lacroix, J.C. Formation of a bifunctional redox system using electrochemical reduction of platinum in ferrocene based ionic liquid and its reactivity with aryldiazonium. J. Am. Chem. Soc. 2013, 135, 4722-4728. [CrossRef] [PubMed]

8. Gao, Y.; Twamley, B.; Shreeve, J.N.M. The first (ferrocenylmethyl) imidazolium and (ferrocenylmethyl) triazolium room temperature ionic liquids. Inorg. Chem. 2004, 43, 3406-3412. [CrossRef] [PubMed]

9. Miura, Y.; Shimizu, F.; Mochida, T. Preparation, properties, and crystal structures of organometallic ionic liquids comprising 1-ferrocenyl-3-alkylimidazolium-based salts of bis(trifluoromethanesulfonyl) amide and hexafluorophosphate. Inorg. Chem. 2010, 49, 10032-10040. [CrossRef] [PubMed]

10. Nyamori, V.O.; Gumede, M.; Bala, M.D. Synthesis, characterisation and properties of ferrocenylalkylimidazolium salts. J. Organomet. Chem. 2010, 695, 1126-1132. [CrossRef]

11. Venker, A.; Vollgraff, T.; Sundermeyer, J. Ferrocenyl-sulfonium ionic liquids-synthesis, characterization and electrochemistry. Dalton Trans. 2018, 47, 1933-1941. [CrossRef] [PubMed]

12. Béguin, F.; Raymundo-Piñero, E.; Frackowiak, E. Electrical double-layer capacitors and pseudocapacitors. In Carbons for Electrochemical Energy Storage and Conversion Systems; CRC Press: Boca Raton, FL, USA, 2010.

13. Nakano, H.; Sugiyama, Y.; Morishita, T.; Spencer, M.J.; Snook, I.K.; Kumai, Y.; Okamoto, H. Anion secondary batteries utilizing a reversible $\mathrm{BF}_{4}$ insertion/extraction two-dimensional Si material. J. Mater. Chem. A 2014, 2, 7588-7592. [CrossRef]

14. Khrizanforov, M.N.; Shekurov, R.P.; Ermolaev, V.V.; Arkhipova, D.M.; Miluykov, V.A.; Kataeva, O.N.; Khrizanforova, V.V.; Budnikova, Y.H. Novel phosphonium salt for paste electrode to study the redox properties of insoluble compounds. Phosphorus Sulfur Silicon Relat. Elem. 2016, 191, 1611-1612. [CrossRef]

15. Wang, W.; Balasubramanian, R.; Murray, R.W. Electron transport and counterion relaxation dynamics in neat ferrocenated imidazolium ionic liquids. J. Phys. Chem. C 2008, 112, 18207-18216. [CrossRef]

16. Teimuri-Mofrad, R.; Rahimpour, K.; Rezaei, H.; Valizadeh, H.; Aghaiepour, A. Study of new synthesized ferrocenyl ionic liquids in oxidative esterification reaction. Synth. Commun. 2018, 48, 1425-1435. [CrossRef]

17. Khrizanforov, M.N.; Arkhipova, D.M.; Shekurov, R.P.; Gerasimova, T.P.; Ermolaev, V.V.; Islamov, D.R.; Miluykov, V.A.; Kataeva, O.N.; Khrizanforova, V.V.; Budnikova, Y.H. Novel paste electrodes based on phosphonium salt room temperature ionic liquids for studying the redox properties of insoluble compounds. J. Solid State Electrochem. 2015, 19, 2883-2890. [CrossRef]

18. Gryaznova, T.; Dudkina, Y.; Khrizanforov, M.; Sinyashin, O.; Kataeva, O.; Budnikova, Y. Electrochemical properties of diphosphonate-bridged palladacycles and their reactivity in arene phosphonation. J. Solid State Electrochem. 2015, 19, 2665-2672. [CrossRef]

19. Khrizanforov, M.N.; Fedorenko, S.V.; Strekalova, S.O.; Kholin, K.V.; Mustafina, A.R.; Zhilkin, M.Y.; Khrizanforova, V.V.; Osin, Y.N.; Salnikov, V.V.; Gryaznova, T.V.; et al. A Ni(III) complex stabilized by silica nanoparticles as an efficient nanoheterogeneous catalyst for oxidative $\mathrm{C}-\mathrm{H}$ fluoroalkylation. Dalton Trans. 2016, 45, 11976-11982. [CrossRef] [PubMed]

20. Khrizanforov, M.N.; Fedorenko, S.V.; Mustafina, A.R.; Kholin, K.V.; Nizameev, I.R.; Strekalova, S.O.; Grinenko, V.V.; Gryaznova, T.V.; Zairov, R.R.; Mazzaro, R.; et al. Silica-supported silver nanoparticles as an efficient catalyst for aromatic C-H alkylation and fluoroalkylation. Dalton Trans. 2018, 47, 9608-9616. [CrossRef] [PubMed]

21. Taidakov, I.; Ambrozevich, S.; Saifutyarov, R.; Lyssenko, K.; Avetisov, R.; Mozhevitina, E.; Khomyakov, A.; Khrizanforov, M.; Budnikova, Y.; Avetissov, I. New Pt (II) complex with extra pure green emission for OLED application: Synthesis, crystal structure and spectral properties. J. Organomet. Chem. 2018, 867, 253-260. [CrossRef]

22. Kataeva, O.; Khrizanforov, M.; Budnikova, Y.; Islamov, D.; Burganov, T.; Vandyukov, A.; Lyssenko, K.; Mahns, B.; Nohr, M.; Hampel, S.; et al. Crystal growth, dynamic and charge transfer properties of new coronene charge transfer complexes. Cryst. Growth Des. 2015, 16, 331-338. [CrossRef] 
23. Kataeva, O.; Metlushka, K.; Ivshin, K.; Kiiamov, A.; Alfonsov, V.; Khrizanforov, M.; Budnikova, Y.; Sinyashin, O.; Krupskaya, Y.; Kataev, V.; et al. Electron transfer and unusual chemical transformations of F4-TCNQ in the reaction with Mn-phthalocyanine. Eur. J. Inorg. Chem. 2018, 2018, 3344-3353. [CrossRef]

24. Busacca, C.A.; Eriksson, M.C.; Haddad, N.; Han, Z.S.; Lorenz, J.C.; Zeng, B.; Senanayake, S.H. Practical Synthesis of Di-tert-Butyl-Phosphinoferrocene. Org. Synth. 2013, 90, 316-326. [CrossRef]

25. Voskuil, W.; Arens, J.F. A note on the preparation of chloro-dialkylphosphines. Recl. Trav. Chim. Pays-Bas 1963, 82, 302-304. [CrossRef]

26. Dolganov, A.V.; Belov, A.S.; Novikov, V.V.; Vologzhanina, A.V.; Romanenko, G.V.; Budnikova, Y.G.; Zelinskii, G.E.; Buzin, M.I.; Voloshin, Y.Z. First iron and cobalt (II) hexabromoclathrochelates: Structural, magnetic, redox, and electrocatalytic behavior. Dalton Trans. 2015, 44, 2476-2487. [CrossRef] [PubMed]

27. Ermolaev, V.; Miluykov, V.; Krivolapov, D.; Rizvanov, I.; Zvereva, E.; Katsyuba, S.; Sinyashin, O.; Shmuzler, R. Phosphonium ionic liquids based on bulky phosphines: Synthesis, structure and properties. Dalton Trans. 2010, 39, 5564-5571. [CrossRef] [PubMed]

28. Frisch, M.J.; Trucks, G.W.; Schlegel, H.B.; Scuseria, G.E.; Robb, M.A.; Cheeseman, J.R.; Scalmani, G.; Barone, V.; Petersson, G.A.; Nakatsuji, H.; et al. Gaussian 09 Revision A02; Gaussian, Inc.: Wallingford, CT, USA, 2016.

29. Adamo, C.; Barone, V. Toward Reliable Density Functional Methods without Adjustable Parameters: The PBE0 Model. J. Chem. Phys. 1999, 110, 6158-6170. [CrossRef]

30. Weigend, F.; Ahlrichs, R. Balanced Basis Sets of Split Valence, Triple Zeta Valence and Quadruple Zeta Valence Quality for H to Rn: Design and Assessment of Accuracy. Phys. Chem. Chem. Phys. 2005, 7, 3297. [CrossRef] [PubMed]

31. Grimme, S.; Antony, J.; Ehrlich, S.; Krieg, H. A Consistent and Accurate Ab Initio Parametrization of Density Functional Dispersion Correction (DFT-D) for the 94 Elements H-Pu. J. Chem. Phys. 2010, 132, 154104-154119. [CrossRef] [PubMed]

32. Becke, A.D.; Johnson, E.R. A Density-Functional Model of the Dispersion Interaction. J. Chem. Phys. 2005, 123, 154101-154109. [CrossRef] [PubMed]

33. Johnson, E.R.; Becke, A.D. A Post-Hartree-Fock Model of Intermolecular Interactions: Inclusion of Higher-Order Corrections. J. Chem. Phys. 2006, 124, 174104-174109. [CrossRef] [PubMed]

34. Grimme, S.; Ehrlich, S.; Goerigk, L. Effect of the Damping Function in Dispersion Corrected Density Functional Theory. J. Comput. Chem. 2011, 32, 1456-1465. [CrossRef] [PubMed]

Sample Availability: Samples of the compounds are available from the authors.

(C) 2018 by the authors. Licensee MDPI, Basel, Switzerland. This article is an open access article distributed under the terms and conditions of the Creative Commons Attribution (CC BY) license (http:/ / creativecommons.org/licenses/by/4.0/). 